
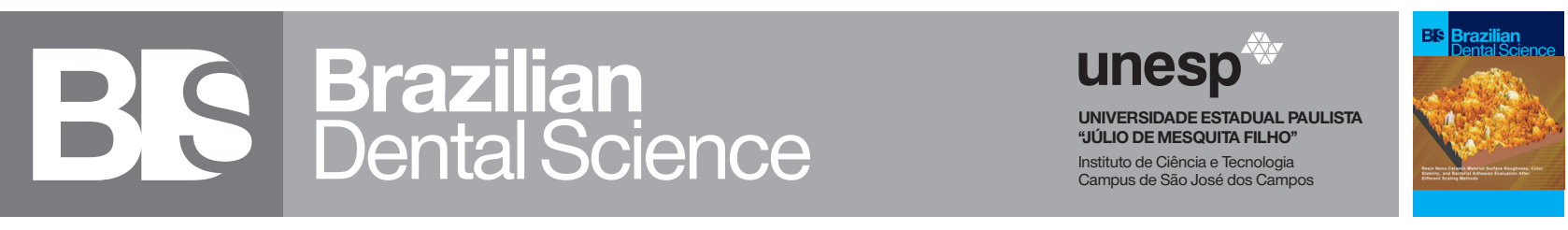

\title{
Prevalence and Configuration of C-shaped Canals in Lower Molars from a Chilean Subpopulation
}

\author{
Prevalência e configuração de canais em forma de C em molares inferiores em subpopulação Chilena \\ Fernando PEÑA-BENGOA ${ }^{1}$, Carlos IBAÑEZ ${ }^{2}$, Paula ERICES ${ }^{2}$, Patricio MELÉNDEZ ${ }^{3}$, Carolina CÁCERES ${ }^{1}$ \\ 1 - Universidad Andres Bello, Department of Endodontics, Viña del Mar, Chile. \\ 2 - Undergraduate student, Universidad Andres Bello, Viña del Mar, Chile. \\ 3 - Universidad Andres Bello, Department of Oral and Maxillofacial Imaging, Viña del Mar, Chile.
}

\section{ABSTRACT}

Objective: To determine the prevalence of C-shaped canals in lower molars (first and second molars) in a Chilean subpopulation, and to identify root configuration and demographic characteristics using cone beam tomography. Materials and method: 912 molars (456 first and 456 second molars) resulting from the analysis of 228 mandibular CBCT scans (89 men and 139 women between 15 and 80 years old) were evaluated. Through panoramic reconstruction and axial tomographic sections, the root configuration was established, and the presence and type of C-shaped canal were classified, analyzing 5 levels along the root canal. Data were statistically analyzed with a 5\% significance level. Results: Of the 912 molars analyzed, 69 were classified as C-shaped (7.57\%), constituting $65.72 \%$ of those molars that presented fused roots. 100\% of this configuration of canals was observed in lower second molars, presenting a higher prevalence in women $(\mathrm{n}=49,71.01 \%)$. $40.82 \%$ of the cases that presented a C-shaped configuration manifested bilaterally. The most frequent C-shaped canal configuration was C3 ( $\mathrm{n}=347,66.10 \%)$, according to Melton's classification. Conclusion: The C-shaped canals in the studied population were observed entirely in lower second molars, showing a clear predilection for the female sex and a high rate of bilaterality.

\section{KEYWORDS}

Anatomy; Cone beam computed tomography; Dental pulp cavity; Endodontics.

\section{RESUMO}

Objetivo: Determinar a prevalência de canais em forma de $\mathrm{C}$ em molares inferiores (primeiros e segundos molares) em uma subpopulação chilena e identificar a configuração radiculares e características demográficas utilizando tomografia feixe cônico. Material e Métodos: Foram avaliados 912 molares ( 456 primeiros e 456 segundos molares) resultando da análise de 228 tomografias de feixe cônico de mandíbulas (89 homens e 139 mulheres entre 15 e 80 anos). Através da reconstrução panorâmica e secções axiais de tomografias, a configuração da raiz foi estabelecida e a classificada a presença e tipo de canal em forma de $\mathrm{C}$, analisando 5 níveis ao longo do canal radicular. Os dados foram analisados estatisticamente com significância de 5\%. Resultados: Dos 912 molares analisados, 69 foram classificados como formato de C $(7,57 \%)$, constituindo $65,72 \%$ dos molares que apresentavam raiz fusionadas. 100\% dessas configurações de canais foram observados em segundos molares inferiores, com maior prevalência em mulheres $(\mathrm{n}=49,71,01 \%) .40,82 \%$ dos casos presentes como formato de C manifestaram-se bilateralmente. A maior frequência das configurações do canal em forma de C no canal foram C3 ( $n=347$, $66.10 \%$ ) de acordo com a classificação de Melton. Conclusão: Canais em forma de C no estudo populacional foram observados em sua totalidade nos segundos molares inferiores, demonstrando nítida predileção pelo sexo feminino e alto índice de bilateralidade.

\section{PALAVRAS-CHAVE}

Anatomia; Tomografia computadorizada de feixe cônico; Cavidade Pulpar; Endodontia. 


\section{INTRODUCTION}

$\mathrm{T}$ he root canal system presents large variations in its anatomy, which may have implications during treatment and may affect the prognosis of endodontic therapy. [1] One of these anatomical variations is the C-shaped canals, whose origin comes from a failure in the union process of Hertwig's epithelial sheath on its vestibular and/or lingual surface, generating a cleft. [2] This root canal configuration is most prevalent in lower second molars, although it can also be found with its own anatomical characteristics in lower first molars, upper molars, and lower premolars with less frequency. $[3,4]$

One of the main problems of this type of configuration is the thickness of the root walls due to the high risk of perforation that may present during endodontic treatment. The greatest area of risk is the mesiolingual wall, which constitutes the area of less thickness, especially in the apical third [1,5], meaning it is a high-risk area during biomechanical preparation of the canal system.

The complexity of this type of configuration requires the use of complementary imaging exams that allow for better analysis and planning of the case. Retroalveolar radiographs, which are very useful in routine endodontic treatment, do not provide enough information regarding this type of canal configuration, because they are two-dimensional images that frequently present an over-projection of structures. [6]

The use of cone beam computed tomography (CBCT) has been successfully applied in endodontics, both for the analysis of periapical lesions and highly complex canals, being a useful and versatile tool for the study of C-shaped canals. [7] CBCT has made it possible to accurately assess this type of root configuration and to determine its prevalence in different parts of the world. Various studies have reported incidences that vary between $2.7 \%$ and
44.5\% in Europe and Asia respectively, with a higher proportion in Asian populations [8] depending on the geographic region analyzed. [9]

There is currently little information regarding the prevalence, configuration and demographic characteristics of this type of canal configuration in South America, except in Brazilian populations, making it impossible to extrapolate the available data to other South American countries. The objective of this study is to perform a retrospective tomographic analysis to assess the prevalence, configuration, and bilaterality of C-shaped canals in the lower molars of a Chilean subpopulation.

\section{MATERIALS AND METHODS}

\section{Sample selection}

This study was submitted for review by the local scientific ethics committee, authorizing its development under resolution number 1820. The sample studied corresponded to the population of the continental territory of the Valparaíso Region, Chile. The size of the sample was determined using the known population formula $(1,808,152$ habitants) obtained from the National Statistics Registry of Chile [10], with 95\% confidence and 5\% significance. The expected prevalence of C-shaped canals was $10.6 \%$, obtained from the study "Analysis of the root canal configuration and C-shaped canal frequency of mandibular second molars: a cone beam computed tomography study" [8], which determined a sample size of 228 CBCT scans.

\section{Imaging analysis}

The imaging analysis was performed by two operators, previously calibrated by Cohen's Kappa test, using iCAT Vision software (Imaging Sciences International, Hatfield, United States) in a darkened room with regulated brightness and contrast. The calibration was performed using 10 CBCTs, which were analyzed and 
classified by the same operator. Subsequently, results were compared between both operators, determining the inter-operator concordance.

Samples were obtained from the Department of Oral and Maxillofacial Imaging of the Andres Bello University, using CBCT of patients from the region obtained between 2017 and 2019. A non-probabilistic sampling was carried out for convenience in which a systematic randomized sampling was performed to obtain the 228 CBCT corresponding to the study sample. Those CBCTs with bilateral presence of mandibular first and second molars and complete root formation were included in the study. Those who presented lower molars with endodontic treatment, severe calcifications, root resorption, immature apex, or tomography with image artifacts that caused interference with the analysis were not included.

In the first stage, root configuration was determined in a panoramic view, followed by the evaluation of the presence of C-shaped canals in lower molars. For the analysis of the root configuration, the methodology proposed by Nejaim et al. [11] was implemented, which used a panoramic reconstruction of $20.4 \mathrm{~mm}$ thickness obtained from the CBCT of each patient. In this image, the first and second molars were classified bilaterally according to their root morphology (Figure 1).

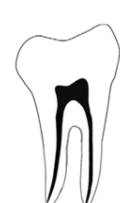

NFR I
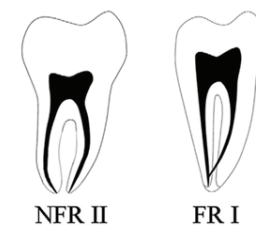

FR I

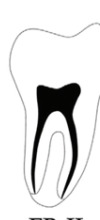

FR II

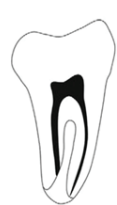

FR III

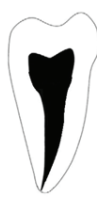

SS
Figure 1 - Classification of root configuration in panoramic reconstruction. NFR I: Parallel or divergent unfused roots; NFR II: Convergent unfused roots; FRI: Conical roots fused with apical convergent mesial and distal canals; FR II: Conical roots fused with both independent mesial and distal canals up to the foramen; FR III: Conical roots fused with a distal canal curved toward a radiolucent line on its way to the apex and the longest mesial canal toward the apex independently; and SS: Conical root fused with a single root canal (obtained from Nejaim et al, 2020).
Subsequently, the presence of C-shaped canals was evaluated using five standardized sections from a multiplanar reconstruction in an axial view [11] (Figure 2), classifying each section according to the classification proposed by Melton [12] (Figure 3). The configuration of the canals was considered to be C-shaped when presenting simultaneously: root fusion, a longitudinal groove on the lingual or buccal surface, and at least one of the five axial cuts classified as C1, C2, or C3.

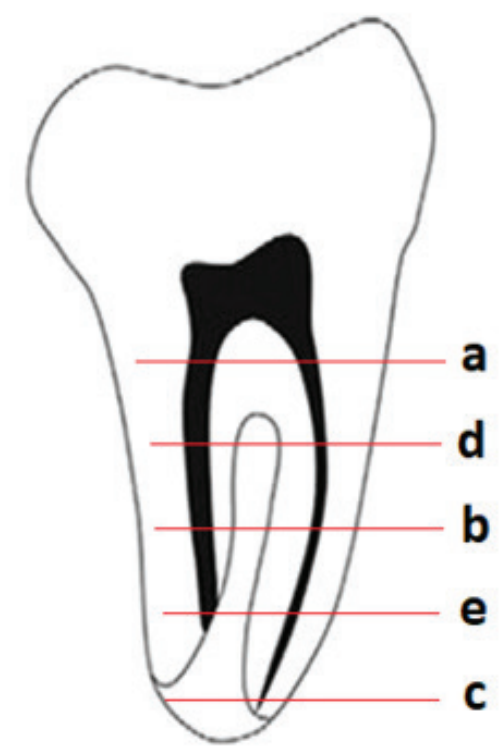

Figure 2 - Cut points established to classify C-shaped canals, according to the methodology used by Nejaim et al, 2020. A: $2 \mathrm{~mm}$ below the entrance of the canals (considered from the cameral floor observed in the middle part of the tooth in the direction vestibule-lingual); B: mean distance between $\mathrm{A}$ and $C$; C: $2 \mathrm{~mm}$ above the anatomical apex; D: mean distance between $\mathrm{A}$ and $\mathrm{B}$; and $\mathrm{E}$ : mean distance between $\mathrm{B}$ and $\mathrm{C}$.

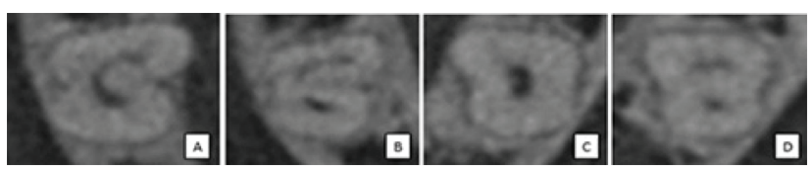

Figure 3 - Melton classification for C-shaped canals. A: C1, "C" continuous; B: C2, Semicolon; C and D: C3, single canal, or 2 semicircular canals independent of each other.

\section{Data analysis plan}

An exploratory data analysis was performed to obtain the descriptive statistics and 
a proportions test was performed to compare the prevalence between variables. The data obtained were analyzed by the statistical software Stata 11.2 (StataCorp LLC, Texas, United States) with a significance level of $5 \%$

\section{RESULTS}

The results of the operator's calibration showed optimal levels of inter-operator agreement, obtaining a kappa value of 0.8 for the root configuration and 0.91 for the classification of C-shaped canals.

Of a total of 912 mandibular molars evaluated, $7.57 \%(n=69)$ were classified as C-shaped, where all the cases presented in second molars. Furthermore, a marked predisposition for the female sex could be observed, showing statistically significant differences with respect to men (Table I).

Table I - Distribution by sex for mandibular molars classified as C-shaped

\begin{tabular}{|cccc|}
\hline Sex & Total & Percentage & IC95\% \\
\hline Male & 20 & 28.99 & $18.69-41.16$ \\
\hline Female & 49 & 71.01 & $58.84-81.31$ \\
\hline Total & 69 & 100.00 & \\
\hline
\end{tabular}

Regarding the distribution according to age groups, it was observed that the highest proportion of C-shaped canals was found in the range of 25-34 years (40/416 teeth; $9.62 \%$ 95\% CI [6.96-12.86]), followed by the range of 15-24 years (17/288 teeth; 5.90\% 95\% CI [3.48-9.28]) (Table II) (Figure 4). No C-shaped canals were observed in patients older than 54 years; however, despite the differences, age did not show statistically significant values for any of the groups $(\mathrm{p}>0.05)$.

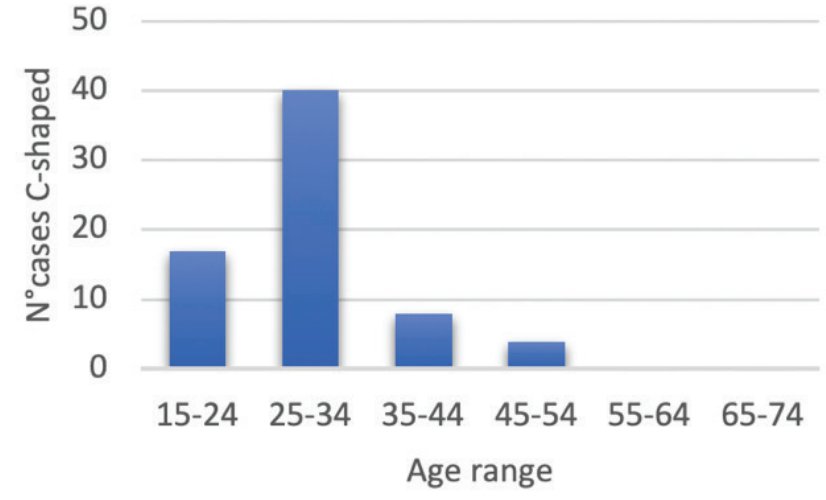

Figure 4 - Distribution of mandibular molars classified as C-shaped according to age range. It was observed that the highest proportion of $\mathrm{C}$-shaped canals was found in the range of 25-34 years, followed by 15-24 years. No cases were observed in the groups ranging from 55-74 years old.

Table II - Distribution of C-shaped canals according to age group

\begin{tabular}{|ccccc|c|}
$\begin{array}{c}\text { Age } \\
\text { group } \\
\text { [years] }\end{array}$ & $\begin{array}{c}\text { Analyzed C-shaped } \\
\text { samples }\end{array}$ & $\begin{array}{c}\text { Percentage } \\
\text { cases }\end{array}$ & $\begin{array}{c}\text { Percentage from } \\
\text { analyzed sam- } \\
\text { ples [\%] (IC95\%) }\end{array}$ & $\begin{array}{c}\text { Petal of C-shaped } \\
\text { to] (IC95\%) }\end{array}$ \\
\hline $15-24$ & 288 & 17 & $5.90(3.39-9.28)$ & $24.64(15.05-36.49)$ \\
\hline $25-34$ & 416 & 40 & $9.62(6.96-12.86)$ & $57.97(45.48-69.76)$ \\
\hline $35-44$ & 112 & 8 & $7.14(3.13-13.59)$ & $11.59(5.14-21.57)$ \\
\hline $45-54$ & 52 & 4 & $7.69(2.14-18.54)$ & $5.80(1.60-14.18)$ \\
\hline $55-64$ & 20 & 0 & 0 & 0 \\
\hline $65-74$ & 24 & 0 & 0 & 0 \\
\hline Total & 912 & 69 & & 100.00 \\
\hline
\end{tabular}

From the 49 patients who presented a C-shaped canal, 20 of them presented bilaterally (40.82\%, 95\% CI [27.00-55.79]), 6 being men and 14 women, verifying that sex was not statistically significant in the distribution of bilaterality of C-shaped canals ( $\mathrm{p}=0.3858)$.

The presence of the C-shaped configuration was associated with molars with fused roots in $100 \%$ of the cases (FRI, FRII, FRIII, and SS) (Table III). When analyzing the configuration in axial sections of the C-shaped canals according to the Melton's classification, a significantly higher percentage of the C3 configuration type was observed over C1 and C2 (Table IV). 
Table III - Distribution of C-shaped molars according to root configuration

\begin{tabular}{|cccc|}
$\begin{array}{c}\text { Root } \\
\text { Configuration }\end{array}$ & $\begin{array}{c}\text { Analyzed C-shaped } \\
\text { samples }\end{array}$ & $\begin{array}{c}\text { Percentage from total of } \\
\text { canals }\end{array}$ & $\begin{array}{c}\text { analyzed samples [\%] } \\
\text { (IC95\%) }\end{array}$ \\
\hline NFRI & 409 & 0 & 0 \\
\hline NFRII & 398 & 0 & 0 \\
\hline FRI,FRII,FRIII y SS & 105 & 69 & $65.72(55.81-74.70)$ \\
\hline Total & 912 & 69 & $7.57(5.93-9.48)$ \\
\hline
\end{tabular}

Table IV - C-shaped configuration at the different levels in axial sections according to Melton's classification

\begin{tabular}{|cccccccc|}
\hline C-shaped & & a & b & c & d & e & Total \\
\hline C1 & Count & 16 & 27 & 15 & 21 & 19 & 98 \\
\hline & $\%$ & $15.24 \%$ & $25.71 \%$ & $14.29 \%$ & $20.00 \%$ & $18.10 \%$ & $18.67 \%$ \\
\hline C2 & Count & 28 & 13 & 5 & 26 & 8 & 80 \\
\hline & $\%$ & $26.67 \%$ & $12.38 \%$ & $4.76 \%$ & $24.76 \%$ & $7.62 \%$ & $15.24 \%$ \\
\hline C3 & Count & 61 & 65 & 85 & 58 & 78 & 347 \\
\hline & $\%$ & $58.10 \%$ & $61.90 \%$ & $80.95 \%$ & $55.24 \%$ & $74.29 \%$ & $66.10 \%$ \\
\hline Total & Count & 105 & 105 & 105 & 105 & 105 & 525 \\
\hline & $\%$ & $100.00 \%$ & $100.00 \%$ & $100.00 \%$ & $100.00 \%$ & $100.00 \%$ & $100.00 \%$ \\
\hline
\end{tabular}

\section{DISCUSSION}

Studies to determine the prevalence of $\mathrm{C}$-shaped canals have gained great relevance due to their complexity and variability [11]. However, there is consensus that this anatomical variation has a higher prevalence in mandibular second molars regarding first mandibular molars $[13,14]$.

The present study observed a prevalence of $7.60 \%$ of C-shaped canals in mandibular molars, where all cases were observed in second molars. The higher prevalence of C-shaped canals in second molars coincides with reports from other studies conducted in South America [11] and the Middle East $[15,16]$.

The limited information regarding the prevalence and configuration of C-shaped canals in South America makes it difficult to compare these results with other studies of the region.
The available evidence is limited in a significant number to studies of Brazilian populations, which may not be representative for other South American countries.

When comparing the results obtained with other studies carried out in Latin America, a lower prevalence can be observed compared with populations in Mexico (14.20\%) and Brazil (15.30\%) [11]. However, these results agree with those of another study carried out in the Chilean population, where a lower proportion was observed compared with other Latin American countries [17]. This difference can be attributed to the ethnicity and geographical location of the population studied, with more importance in comparisons made with Asian countries [18]. The higher prevalence shown in the studies from Brazil and Mexico may be attributed to a large number of resident foreign colonies, which increases ethnic variability. Despite these claims, Martins et al. [19] consider that there are no anthropological studies that can fully substantiate this point.

Regarding the distribution of C-shaped canals in relation to age, the highest proportion of C-shaped canals was observed in the group aged 25-34 years (9.62\%), followed by the group aged $15-24$ years (5.90\%). Despite this distribution difference, age was not found to be significant in any group. A lower prevalence of this type of canal was observed in the older age groups, which may be attributed to the fact that over time, the number of molars in the mouth decreases, and thus many patients in advanced age ranges did not meet the inclusion criteria to be entered into the present study.

Regarding the distribution of C-shaped canals in relation to sex, a marked trend towards the female sex was observed, which has also been observed in similar studies carried out in Korea [15], Portugal [3], and Saudi Arabia [20], in addition to global studies $[18,8]$ and a recent systematic review by Martins et al. [19]. 
Of the total number of patients with C-shaped canals, $40.82 \%$ presented bilaterally. Despite the variation in the distribution of bilaterality, the results are similar to those obtained in Brazil [6] and lower compared to studies carried out in Asia, where the percentages of bilaterality were reported to vary between 70-81\% [13]. When observing the bilaterality in relation to sex, no significant difference was found between both groups.

Regarding the distribution of the C-shaped configuration in the axial sections, according to Melton's classification, a higher prevalence of the C3 type was observed, while the C1 and C2 configurations were lower and presented similar values to each other. This implies a great variability in the anatomy of the analyzed root canals, demonstrating a tendency to be confluent or two completely independent canals leading to the apical foramen.

Of all the molars analyzed, a significant proportion of C-shaped canals (65.71\%) were observed in molars that presented fused roots (FRI, FRII, FRIII, and SS). This result is consistent with the results of Nejaim et al. [11], where mandibular molars with fused roots were 17.2 times more likely to present C-shaped canals than those with unfused roots. This implies that when observing fused roots in preoperative radiographs, they should correlate with a high probability of presenting C-shaped root canals. This important relationship between fused roots and C-shaped canals should alert the clinician to perform a diagnosis and a pretreatment planning supported by CBCT images, allowing to treat this type of root canal configuration accurately and safely to ensure a good prognosis of the endodontic treatment.

Future studies of other Chilean subpopulations are necessary to obtain representative results of the Chilean country. The methodology used in the present study can serve as the basis for future studies that lead to obtain the prevalence, configuration and demographic characteristics of the C-shaped canals of the entire Chilean population.

\section{CONCLUSION}

The C-shaped canals of the studied subpopulation were observed completely in lower second molars, showing a clear predilection for the female sex and a high rate of bilaterality. The presence of fused roots is directly related to a high probability of finding C-shaped canals in lower second molars.

\section{Acknowledgments}

None

\section{Funding}

This study did not receive any type of funding.

\section{Conflict of interest}

The authors declare no conflicts of interest.

\section{Regulatory Statement}

This study was conducted in accordance with all the provisions of the local human subject's oversight committee guidelines and policies of the Faculty of Dentistry of the Andres Bello University, Viña del Mar, Chile. The approval code for this study is: 1820 .

\section{REFERENCES}

1. Kim Y,Lee D, Kim DV, Kim SY. Analysis of cause of endodontic failure of C-shaped root canals. Scanning. 2018 Nov 25;2018:2516832. doi: $101155 / 2018 / 2516832$.

2. Fan B, Cheung GSP,Fan M, Gutmann JL, Bian Z. C-shaped canal system in mandibular second molars: Part I - Anatomical features. JEndod. 2004;30(12): 899-903. doi: 10.1097/01.don.0000136207.12204.e4.

3. Martins JNR, Mata A, Marques D, Caramês J. Prevalence of C-shaped mandibular molars in the Portuguese population evaluated by cone-beam computed tomography. Eur J Dent. 2016;10(4):529-35. doi: 10.4103/13057456.195175 .

4. Martins JNR, Francisco H, Ordinola-Zapata R. Prevalence of C-shaped configurations in the mandibular first and second premolars: a cone-beam computed tomographic in vivo Study. J Endod. 2017;43(6):890-95. doi: 10.1016/j.joen.2017.01.008. 
5. Chai WL, Thong YL. Cross-sectional morphology and minimum canal wall widths in C-shaped roots of mandibular molars. J Endod. 2004;30(7):509-12. doi:10.1097/00004770-200407000-00012.

6. Ladeira DBS, Cruz AD, Freitas DQ, Almeida SM. Prevalence of C-shaped root canal in a Brazilian subpopulation: a cone-beam computed tomography analysis. Braz Oral Res. 2014;28:39-45. doi: 10.1590/S180683242013005000027.

7. Krug R, Connert T, Beinicke A, Soliman S, Schubert A, Kiefner P, et al. When and how do endodontic specialists use cone-beam computed tomography? AustEndod J. 2019 Dec;45(3):365-72. doi: 10.1111/aej.12337.

8. Tassoker M, Sener S. Analysis of the root canal configuration and C-shaped canal frequency of mandibular second molars: a cone beam computed tomography study. Folia Morphol (Warsz). 2018;77(4):752-7. doi: 10.5603/ FM.a2018.0040.

9. Kato A, Ziegler A, Higuchi N, Nakata K, Nakamura H, Ohno N. Aetiology, incidence and morphology of the $\mathrm{C}$-shaped root canal system and its impact on clinical endodontics. Int Endod J. 2014;47:1012-33. doi: 10.1111/iej.12256.

10. Instituto Nacional de Estadísticas [Internet].Síntesis De Resultados Censo 2017 Instituto. Avalilable in: https://www.censo2017.cl/descargas/home/ sintesis-de-resultados-cens02017.pdf.

11. Nejaim Y, Gomes AF, Rosado L de PL, Freitas DQ, Martins JNR, da Silva EJNL. C-shaped canals in mandibular molars of a Brazilian subpopulation: prevalence and root canal configuration using cone-beam computed tomography. Clin Oral Investig. 2020;24(9):3299-305. DOl: 10.1007/s00784020-03207-6.

12. Melton DC, Krell K V, Fuller MW. Anatomical and histological features of C-shaped canals in mandibular second molars. J Endod. 1991;17(8):384-88. doi:10.1016/S0099-2399(06)81990-4.

13. Fernandes M, De Ataide I, Wagle R. C-shaped root canal configuration: a review of literature. J Conserv Dent. 2014;17(4):312-19. doi:10.4103/09720707.136437.
14. Vaz De Azevedo KR, Lopes CB, Andrade RHTLR, Pacheco da Costa FFN, Gonçalves LS, Medeiros Dos Santos R, et al. C-shaped canals in first and second mandibular molars from Brazilian individuals: A prevalence study using cone-beam computed tomography. PLoS ONE. 2019; 14(2), e0211948. doi: 10.1371/journal.pone.0211948.

15. Kim SY, Kim BS, Kim Y.Mandibular second molar root canal morphology and variants in a Korean subpopulation. Int Endod J. 2016;49(2):136-44. doi: 10.1111/iej.12437.

16. Shemesh A, Levin A, Katzenell V, Itzhak JB, Levinson 0, Avraham Z, et al. C-shaped canals-prevalence and root canal configuration by cone beam computed tomography evaluation in first and second mandibular molars-a cross-sectional study. Clin Oral Investig. 2017;21(6):2039-44. doi:10.1007/ s00784-016-1993-y.

17. Torres A, Jacobs R, Lambrechts P, Brizuela C, Cabrera C, Concha G, et al. Characterization of mandibular molar root and canal morphology using cone beam computed tomography and its variability in Belgian and Chilean population samples. Imaging Sci Dent. 2015 Jun;45(2):95-101. doi: 10.5624/ isd.2015.45.2.95.

18. von Zuben M, Martins JNR, Berti L, Cassim I, Flynn D, Gonzalez JA, Gu Y, Kottoor J, Monroe A, et al. Worldwide prevalence of mandibular second molar c-shaped morphologies evaluated by cone-beam computed tomography.J Endod. 2017 Sep;43(9):1442-7. doi:10.1016/j.joen.2017.04.016

19. Martins JNR, Marques D, Silva EJNL, Caramês J, Mata A, Versiani MA. Prevalence of C-shaped canal morphology using cone beam computed tomography - a systematic review with meta-analysis. Int Endod J. 2019;52(11):1556-72. doi: 10.1111/iej.13169.

20. Alfawaz H, Alqedairi A, Alkhayyal AK, Almobarak AA, Alhusain MF, Martins JNR. Prevalence of C-shaped canal system in mandibular first and second molars in a Saudi population assessed via cone beam computed tomography: a retrospective study. Clin Oral Investig. 2019;23(1):107-12. doi: 10.1007/s00784-018-2415-0.

\section{Fernando Peña-Bengoa}

(Corresponding address)

Universidad Andres Bello, Endodontic Department, Viña del Mar, Chile. Full postal address: Calle Quillota 980, torre E, 2531015, Viña del Mar, Chile.

Date submitted: 2020 Dec 22

Accept submission: 2021 Feb 01 